Journal of Economics and Behavioral Studies

Vol. 3, No. 1, pp. 42-50, July 2011 (ISSN: 2220-6140)

\title{
Analyzing the Efficiency Differences among Basic Health Units in Sargodha District
}

\author{
Touqeer Abbas ${ }^{1}$, Masood Sarwar Awan ${ }^{1}$, Muhammad Amir Aslam², *Muhammad Waqas ${ }^{1}$ \\ 1 Department of Economics University of Sargodha, Pakistan \\ 2Probation Officer, District Courts Sargodha. Punjab Home Department, Pakistan \\ *economist147@hotmail.com
}

\begin{abstract}
Pakistan has adequate infrastructure for health services delivery at primary level. The study aims to calculate the technical efficiency of Basic Health Units (BHUs) in Sargodha by using the Data Envelopment Analysis (DEA) with the choice of inputs and outputs being specific to BHUs operation. DEA model results reveals that the mean technical efficiency under, Constant Returns to Scale (CRS) and Variable Returns to Scale (VRS) was 0.719 and 0.807 while the mean scale efficiency was 0.88 . Study exposed that $77 \%$ BHUs were technically inefficient under CRS while $66 \%$ BHUs were technically inefficient under VRS modal. Overall $76 \%$ BHUs were inefficient and destructing the infrastructure. Moreover, findings evidently point to adverse inefficiency of BHUs in health services delivery. Study concluded that existing high level of inefficiency in BHUs needs institutional fascination for scaling up BHUs to meet both regional as well international targets such as Millennium Development Goals (MDGs) and recommended such measures that may curb the waste.
\end{abstract}

Key words: Basic Health Units, Technical Efficiency, Data Envelopment Analysis, Pakistan

\section{Introduction}

First decade of this century remains remarkable in the history due to the historic commitment by the 189 heads of states known as Millennium Declaration in 2000 to combat extreme poverty, hunger and ill-health throughout the world. This commitment is summarized in the eight Millennium Development Goals (MDGs) that set targets in areas of poverty reduction, health improvements, education attainment, gender equality, environmental sustainability, and fostering global partnerships (UNDP 2003) ${ }^{1}$. In these goals, health is at the core of achievement. Three of the eight Development Goals, eight of the 18 targets, and 18 of the 48 indicators are health related. Despite the fact that international investments to achieve MDGs by 2015 is in millions dollars with numerous effective, affordable and exceptional interventions to aggrandize the human's well being, it is still inadequate for many countries as natural disasters, terrorism, hunger, poverty and diseases are increasing more rapidly than investments. As discussed earlier, health is the most concerned MDG and on top priority which requires such durable service delivery system that can assure the quality and ease of the services to the population. Last decade of quest for MDGs recognizes the fact that primary health care is the best way to achieve sustainable development and all desired goals.

Pakistan is the on of the higher populated country in the South Asian region with 170.6 millions population. Pakistan has adept basic health services delivery system consisting off BHUs, Rural Health Centers (RHUs), Maternity and Child Health Centers (MCHs), Civil Hospitals and Dispensaries as well. This adequate institutional mechanism for public health services delivery abide by 968 hospitals, 4,813 dispensaries, 5,345 basic health units, 572 rural health centers, 908 maternity and child health centers and 293 TB centers. The BHU is a medical facility located in a rural Union Council which serves 5000-10,000 people in area of 15-25 square miles. The Basic Health Unit aims to provide treatment and medication in rural community, basic health education, antenatal care and basic health of children and women, immunization, and implementation of disease eradication programs such as TB, polio, etc. BHUs can serve as the backbone by making health services accessible for individuals, families and communities.

Basic health is the prime concern of development and in Pakistan BHUs are the health service providers at primary level. Likewise other governmental agencies involved in public services delivery health also should accountable for the services they provide. Accountability of the health services can be done by measuring the

${ }^{1}$ UNDP, 2003 Millennium Development Goals: A Compact among Nations to End Human Poverty. United Nations Development Program, New York. 
technical efficiency of basic health services provided by BHUs. Measurement of technical efficiency remnant in docket of the researcher's since the complementary work of Taylor \& Fayol. Assorted forms of operations research techniques (ORT) exist to measure the technical efficiency of Decision Making Units (DMUs) with various complications. DEA is also a relatively new form of ORT for technical efficiency measurement of DMUs first introduced by Charnes et al. in 1978 to measure the efficiency of DMUs having multiple inputs and outputs. Eager discussion on technical efficiency measurement started in 1980s but major concern of the technical efficiency measurement restricted to hospital level analysis. Evidence from various studies in developed and developing countries showed that prevalence of high level technical inefficiency in health sector lead towards the wastage of available resources. Till now, as far as our knowledge is concerned, no study of technical efficiency in the health sector has been done in Pakistan. Therefore the assessment of technical efficiency of basic health units is essential to utilize the available resources optimally and expedite the move to achieve millennium development goals and better health. Present study examines the technical and scale efficiencies of 116 BHUs in Sargodha by using Data Envelopment Analysis.

\section{Systematic Review}

Data Envelopment Analysis is widely appreciated by numerous countries to inspect efficiency of services. Banker, Conrad \& Strauss (1986) first used DEA in health sector of US to study the hospital production. Eventually DEA becomes accredit tool of efficiency analysis in the health sector. Review of concerned literature is mentioned below.

Dash et al. (2010) measured the technical and scale efficiencies of public district hospitals in Tamil Nadu, India. Study used the data of 29 districts hospitals for the year 2004-2005, collected and administered by the Directorate of Medical and Rural Health Services, Tamil Nadu. Technical and scale efficiencies were assessed by using DEA. Output variables include number of inpatients, number of outpatient visits, number of child deliveries, number of surgeries, and number of emergency cases attended, while number of staff and number of beds were used as input variables. $52 \%$ of the hospitals were technically efficient while, the remaining $48 \%$ were technically inefficient. Average scale efficiency of inefficient hospitals was 0.81. Ismail (2010) estimated the technical efficiency of states health institutions in Sudan. Study used the annual data of 15 states of Sudan for the year of 2007 published by the Federal Ministry of Health. Output-orientated DEA model was applied to estimate the technical efficiency of states. Output variables include number of inpatients and outpatients, while input variables were number of hospitals, number of health centers, number of beds, number of physicians and other medical staff. $40 \%$ of the states were technically inefficient under CRS while $33 \%$ states were technically inefficient under VRS. 40\% states were scale inefficient of which, 3 states were operating under variable returns to scale while remaining were operating under decreasing returns to scale.

Akazili et al. (2008) evaluate the technical efficiency of public health centers in Ghana. Study used the primary data of 89 health centers in Ghana collected in 2005. DEA was applied to determine the degree of efficiency of health centers. Study employed human resources (clinical and non- clinical staff), total expenditures on drugs and other consumables and number of beds as the inputs of health center and out patient visits, number of antenatal visits, number of deliveries, number of child immunized and number of family planning visits as the outputs of health center. Finding showed that $65 \%$ of the health centers were technically inefficient and were wasting the provided resources. Jemai (2007) examined the effectiveness of health care system in African and Arab Countries. Study exploited the hospital data of 37 countries $(18$ African countries and 19 Arab countries) for the year 1998-2005 collected by World Health Organization and the World Bank. Three DEA models were used to measure technical efficiency. Death rate under five years, life expectancy at birth and good health were used as output variables and number of physicians and beds per 1000 inhabitants and amount of total expenditure on health were used as input variables. Mean efficiency scores of the health sectors were 0.74 for the three Models. The most efficient countries had the weakest total health expenditure (DEA1 and DEA3). Increase of input reduced the efficiency scores of health system.

Alvarado (2006) examined the productive efficiency of the primary health care centers of Chile. Study used the cross sectional data of 24 Chilean municipalities located in the urban area for the year 2001. DEA was employed to evaluate technical and scale efficiencies. Study used two inputs (personnel and operational costs) and two outputs (number and time of visits corresponding to each municipality) to evaluate efficiency. 
The results showed 5 municipalities were totally efficient, 6 were Constant Returns to Scale efficient, 9 were VRS efficient and 9 were scale efficient. Efficiency was affected by the administration of health centers by the local governments. Zere et al. (2006) determined the technical and scale efficiencies of district hospitals of Namibia. Study used the panel data of 30 public sector hospitals for four financial years 1997-98-2000-01. DEA was used to assess technical efficiency. Total recurrent expenditure, number of nurses and number of beds were used as input variables and total number of outpatient visits and inpatient days were used as output variables. Average efficiency level during the period was less than 0.75 . Less than half of the hospitals were on the technically efficient frontier. Increasing return to scale was observed to be the predominant form of scale efficiency.

Renner et al. (2005) measured the technical and scale efficiencies of public health units (PHUs) in Pujehun district of Sierra Leone. Study used the cross-sectional data of 37 PHUs, collected and administered by Pujehun district health team. DEA was applied to assess the technical and scale efficiencies. DEA scores were appraised by using vaccinator, community health nurse, emergency and humanitarian officer, sub- ordinate staff, materials and capital as input variables and number of antenatal care visits, number of babies delivered, number of nutrition/growth monitoring visits, number of child under five immunized and number of health education session conducted by PHU as output variables. Out of 37 peripheral health units (PHUs), 41 percent were technically efficient. Remaining 59 percent were technically inefficient, with an average efficiency score of 0.63. 65 percent health units were scale inefficient, with an average scale inefficiency score of 0.72 .

\section{Data Sources and Methodology}

Study used the data of 116 Basic BHUs in district Sargodha for the year 2010. Data was managed by the Statistical department of the district health office, in the shape of monthly reports from all BHUs of the district. Four, outputs and inputs were used to evaluate the efficiency of the BHUs. Input variables are Number of Medical staff, Number of Para-medical staff, Number of Lady Health Workers, Number of other staff while, Number of out door patients, Number of Child immunized, Number of Family Planning Visits and Number of First Antenatal care visits are output variables.

Data Envelopment Analysis: Data Envelopment Analysis is non parametric linear programming method used to evaluate the relative efficiency of each production unit among fairly homogenous DMUs. The location the shape of efficiency frontier is determined by the data, using simple notion that a DMU that employs less inputs than other to produce same level of output, is considered more efficient. DEA evaluate efficiency in two stages: first it identifies a frontier based on DMUs usage of input and output mix then compares the other DMUs in data with the DMUs lying on the frontier. Efficiency in DEA is defined as a ratio of weighted sum of outputs of DMUs by Weighted sum of inputs.

Efficiency $=$ Weighted sum of outputs $/$ weighted sum of inputs

Technical efficiency of each decision making unit is computed by solving the following mathematical program:

$\max \left[\frac{\sum_{s=1}^{S} u_{s} \times y_{s 1}}{\sum_{n=1}^{N} v_{n} \times x_{n 1}}\right]$

$$
\begin{aligned}
& \text { Subject to: } \\
& \frac{\sum_{s=1}^{S} u_{s \times y_{s i}}}{\sum_{n=1}^{N} v_{n 1} \times x_{n i}} \leq 1 \quad \mathrm{i}=1, \ldots, \mathrm{I} \\
& y_{s 1-Q \text { wantity of output } S \text { for } D M U_{1}}
\end{aligned}
$$

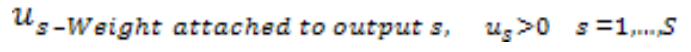

$$
\begin{aligned}
& x_{n 1-Q \text { uantity of output } N \text { for } D M U_{1}}
\end{aligned}
$$

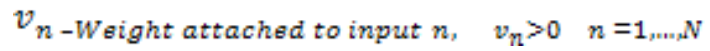

The linear program seeks out for decision making unit $\mathrm{DMU}_{1}$ the set of input weights $\mathrm{v}_{\mathrm{n}}$ and output weights $\mathrm{u}_{\mathrm{s}}$ that maximizes the efficiency of $\mathrm{DMU}_{1}$. 
Constant Returns to Scale (CRS) Model: Charnes, Cooper \& Rhodes (1978) presented CRS which, consider that all the DMUs under consideration are being operated at optimal scale. The functional programming model can be converted into linear programming model by imposing the following constraint:

$$
\sum_{n=1}^{N} v_{n} \times x_{n i}=1
$$

Thus, the relative efficiency of $\mathrm{DMU}_{1}$ can be measured by solving the following equation:

$$
\text { Efficiency }=\max \mathrm{u}_{\mathrm{s}}, \mathrm{V}_{\mathrm{n}} \sum_{s=1}^{S} \mathrm{u}_{\mathrm{s}} y_{s p}
$$

$$
\begin{aligned}
& \text { Subject to: } \\
& \sum_{s=1}^{S} u_{s} y_{s i}-\sum_{n=1}^{N} v_{n} x_{n i} \leq 0 \\
& \sum_{n}^{N} v_{n} x_{n p}=1 \\
& u_{s}, v_{n} \geq 0
\end{aligned}
$$

The Variable Returns to Scale (VRS) Model: Banker, Charnes and cooper (1984) extended DEA to accommodate a more flexible VRS model which may be appropriate when all DMUs are not operating at an optimal scale. In this situation technical efficiency measure will be mixed with scale efficiency. VRS model an additional convexity constraint is imposed on the CRS model. The relative efficiency score of the hospital $p$ can be obtained by solving the following:

Efficiency $=\max \mathrm{u}_{\mathrm{s},} \mathrm{v}_{\mathrm{n}} \sum_{s=1}^{S} \mathrm{u}_{\mathrm{s}} y_{s p}+u_{0}$

$$
\begin{aligned}
& \text { Subject to: } \\
& \sum_{s=1}^{s} u_{s} y_{s i}-\sum_{n=1}^{N} v_{n} x_{n i}+u_{o} \leq 0 \\
& \sum_{n}^{N} v_{n} x_{n p}=1 \\
& u_{s}, v_{n} \geq 0
\end{aligned}
$$

$u_{\circ}$ is convexity constraint and its sign determines the returns to scale. If $u_{\circ}<0$ it shows increasing returns to scale, if $u_{\circ}>0$ it shows decreasing to returns to scale, if $u_{\circ}=0$ it shows constant returns to scale. Scale efficiency of hospital can be obtained by the ratio of CRS technical efficiency to the VRS technical efficiency.

\section{Results and Discussion}

Table 1 presents the summary statistics of the input and output variables of the 116 BHUs. Table 2 presents the summary statistics of the input and output variables of the efficient and inefficient BHUs. Results showed that the efficient BHUs had more mean values of the output variables than the inefficient BHUs while, inefficient BHUs had a more mean values of the input variables than the efficient BHUs. 
Table 1: Summary Statistics of Basic Health Centers (BHUs)

\begin{tabular}{lllll}
\hline Variable & Mean & Std. deviation & Min. & Max. \\
\hline Output & & & & \\
Number of out patient visits & 396.03 & 190.286 & 114 & 1142 \\
Number of children immunized & 55.66 & 49.886 & 0 & 460 \\
Number of family planning visits & 28.51 & 18.387 & 0 & 79 \\
Number of first antenatal care visits & 28.59 & 17.811 & 0 & 104 \\
Input & & & & \\
Number of medical staff & 0.71 & 0.457 & 0 & 1 \\
Number of Para medical staff & 6.20 & 1.534 & 1 & 9 \\
Number of lady health workers & 12.03 & 6.896 & 0 & 33 \\
Number of other staff & 3.35 & 2.312 & 0 & 8 \\
\hline
\end{tabular}

Table 2: Summary Statistics of efficient and inefficient Basic Health Centers (BHUs)

\begin{tabular}{|c|c|c|c|c|c|c|c|c|}
\hline \multirow[b]{2}{*}{$\begin{array}{l}\text { Output } \\
\text { Variables }\end{array}$} & \multicolumn{4}{|c|}{ Efficient BHUs } & \multicolumn{4}{|c|}{ Inefficient BHUs } \\
\hline & Mean & $\begin{array}{l}\text { Std. } \\
\text { Dev. }\end{array}$ & Min. & Max. & Mean & $\begin{array}{l}\text { Std. } \\
\text { Dev. }\end{array}$ & Min. & Max. \\
\hline Number of out patient visits & 388.95 & 216.414 & 114 & 1142 & 399.75 & 176.423 & 133 & 998 \\
\hline Number of children immunized & 59.85 & 71.308 & 0 & 460 & 53.45 & 34.021 & 0 & 175 \\
\hline $\begin{array}{l}\text { Number of family planning } \\
\text { visits }\end{array}$ & 32.48 & 22.633 & 0 & 79 & 26.42 & 15.467 & 0 & 72 \\
\hline $\begin{array}{l}\text { Number of first antenatal care } \\
\text { visits }\end{array}$ & 32.78 & 22.741 & 0 & 104 & 26.38 & 14.256 & 0 & 63 \\
\hline Input & & & & & & & & \\
\hline Number of medical staff & 0.48 & 0.506 & 0 & 1 & 0.83 & 0.379 & 0 & 1 \\
\hline Number of Para medical staff & 5.78 & 1.901 & 1 & 8 & 6.42 & 1.257 & 3 & 9 \\
\hline Number of lady health workers & 10.35 & 7.698 & 0 & 32 & 12.91 & 6.310 & 0 & 33 \\
\hline Number of other staff & 2.40 & 2.073 & 0 & 6 & 3.86 & 2.284 & 0 & 8 \\
\hline
\end{tabular}

Table 3 (Appendix) presents the technical and scale efficiency scores and the returns to scale by using the VRS model in the DEA. DEA efficiency scores range from 0 (totally inefficient) to 1 (efficient). Results of VRS DEA model explained that $40(34.48 \%)$ BHUs were technically efficient, while the remaining $76(65.52 \%)$ were technically inefficient. Among the inefficient BHUs $10(8.62 \%)$ had a technical efficiency scores less than 0.50, $32(27.58 \%)$ BHUs had efficiency scores between 0.50 and $0.75,34(29.31 \%)$ BHUs had efficiency scores between 0.75 and 1 . The average technical efficiency score was 0.807 with the standard deviation of 0.21 . Out of this, the inefficient BHUs had average technical efficiency scores of 0.705 with a standard division of 0.19 . This implies that on average inefficient BHUs could reduce their utilization of all inputs by $29.5 \%$ without reducing output. Out of the 116 BHUs analyzed 28(24.13\%) were scale efficient while the remaining 88(75.87\%) were scale inefficient. Among the inefficient BHUs 15(12.93\%) had scale efficiency scores less than $0.75,73$ BHUs $(62.93 \%)$ between 0.75 and 1 . the average scale efficiency score was 0.885 with the standard deviation of 0.109 . the inefficient BHUs had an average scale score of 0.847 with the standard deviation of 0.10 ; implying there is potential for increasing total output by about $15.3 \%$ by using the existing capacity or size of the BHUs.

Among the 116 BHUs, 29(25\%) BHUs exhibited constant returns to scale implying that they were operating at their productive size. 81(69.82\%) BHUs exhibited decreasing returns to scale while, 6(5.18\%) BHUs exhibited increasing returns to scale. Hospitals exhibiting increasing and decreasing returns to scale should expand and scale dawn respectively both their inputs and outputs in order to operate at their most productive size. 


\section{Conclusion and Policy Implications}

Efficiency in basic health services at primary level can pave the way for destination. The present study rationally demonstrated the applicability of DEA in health sector to indentify the least and most efficient BHUs in Sargodha District. Harmonizing capability of DEA for acclimating heterogeneous inputs and outputs is widely accepted and appraised by academia and policy makers which makes it very exceptional scale of efficiency measurement. This study determines the efficiency of BUHs in Sargodha District using the multiple inputs and outputs involved in BHUs operation by adopting DEA model. DEA model results reveals that the mean technical efficiency under, CRS and VRS was 0.719 and 0.807 while the mean scale efficiency was 0.885. Study exposed that $77 \%$ BHUs were technically in efficient under CRS while $66 \%$ BHUs were technically inefficient under VRS modal. Overall 76\% BHUs were inefficient and destructing the infrastructure. The overall findings assented with the communal perception that public health services delivery mechanism in developing countries is technically inefficient. There should be multiple causes of this high level of inefficiency in the BHUs which should be unpacked. Government should allocate more resources on the health sector to curb the ruin infrastructure. Moreover, it is also recommended that similar studies should be taken at all level of health services delivery in the country.

\section{References}

Afonso, A. \& Fernandes, S. (2008). Assessing hospital efficiency: Non-parametric evidence for Portugal. Working paper, Lesbian University Portugal.

Akazili, J., Adjuik, M., Appiah, C. J. \& Zere, E. (2008). Using Data Envelopment Analysis to Measure the Extent of Technical Efficiency of Public Health Centers in Ghana. Bio Med Central Ltd, 20(2), 232-248.

Akazili, J., Adjuik, M., Chatio, S., Kanyomse, E., Hodgson, A., Aikins, M. and Gyapong, J. (2008). What are The Technical and Allocative Efficiencies of Public Health Centers in Ghana. Ghana Medical Journal, 42(4), 149-155.

Alvarado, J. R. (2006). Evaluating Technical Efficiency of Primary Health Care in the Governments of Chile. Working paper, Autonomous University of Barcelona.

Banker, R. D., Charnes, A. \& Cooper, W. W. (1984). Some Models for Estimating Technical and Scale efficiencies in Data Envelopment Analysis. Management Science, 30(9), 1078-1092.

Banker, R. D., Conrad, R., \& Strauss, R. (1986). A Comparative Application of Data Envelopment Analysis and Translog Methods: An illustrative study of hospital production. Management Science, 32(1), 30-44.

Barbetta, G. P., Turati, G. \& Zago, A. M. (2007). Behavioral Difference between Public and Private not-for-profit Hospitals in the Italian National Hospitals. Health Economics, 16(1), 75-96.

Bhatti, M. A. \& Khan, S. A. (2005). Health Facilities (BHUs). Professional Med J, 12(4), 357-363.

Blank, J. L. T. \& Valdmanis, V. G. (2009). Environmental Factors and Productivity on Dutch Hospitals: A SemiParametric Approach. Health Care Management Science, 13(1), 27-34.

Charnes, A., Cooper, W. W. \& Rhodes, E. (1978). Measuring the Efficiency of Decision-Making Units. European Journal of Operational Research, 2(4), 429-444.

Chua, C. L., Palangkaraya, A. \& Yong, J. (2009). Hospital Competition, Technical Efficiency, and Quality. Working Paper, Melbourne Institute Series.

Dash, U., Vaishnavi, S. D. \& Muraleedharan, V. R. (2010). Technical Efficiency and Scale Efficiency of District Hospitals. Journal of Health Management, 12(3), 231-248.

Farell, M. J. (1957). The Measurement of Productive Efficiency. Journal of Royal Statistical Society, 120, 253281.

Government of Pakistan Economic Survey. 2008-2009, 2009-2010. Islamabad: Economic Advisor's Wing, Finance Division.

Ismail, M. A. (2010). Technical Efficiency of Sudan's Health Institutions: A State-level Analysis. Sudanese Journal of Public Health, 5(3), 122-129.

Jemai, J. I. (2007). Total Performance of the Health Systems: A Comparative Study of Arab and African Countries. International Review of Business Research Papers, 3(4), 111-124.

Khan, M. A. (2009). Failure Analysis of Primary Health Care in Pakistan \& Recommendations for change (Research Report). Insaf Research Wing. 
Marschall, P. \& Flessa, S. (2008). Assessing the Efficiency of Rural Health Centers in Burkina Faso: An Application of Data Envelopment Analysis, Journal of Public Health, 17(2), 87-95.

Multiple Indicator Cluster Survey Report, Government of the Punjab Planning \& Development Department Bureau of Statistics (2007-08).

Renner, A., Joses M. K., Eyob, A. Z., Barry, S. P., Kirigia, D. G., Kamara, C., \& Muthuri, L. H. K. (2005). Technical efficiency of peripheral health units in Pujehun district of Sera Leaone: A DEA application, $B M C$ Health Services Research, 5(77), 1-11.

Zere, E., Mbeeli, T., Shangula, K., Mandlhate, C., Mutirua, K., Tjivambi, B., \& Kapenambili, W. (2006). Technical efficiency of district hospitals: Evidence from Namibia using Data Envelopment Analysis, Cost Effectiveness and Resource Allocation, 4(5), 1-9.

Appendix

Table 3: Technical and Scale efficiency scores for Basic Health Units

\begin{tabular}{|c|c|c|c|c|}
\hline $\begin{array}{l}\text { Basic Health Unit } \\
\text { (BHU) }\end{array}$ & $\begin{array}{l}\text { CRS Technical } \\
\text { efficiency Scores }\end{array}$ & $\begin{array}{l}\text { VRS Technical } \\
\text { efficiency Scores }\end{array}$ & $\begin{array}{l}\text { Scale efficiency } \\
\text { Scores }\end{array}$ & Returns to scale \\
\hline BHU Hyderabad town & 0.424 & 0.529 & 0.8 & Decreasing \\
\hline BHU Luqman & 0.799 & 1 & 0.799 & Decreasing \\
\hline BHU Mari & 0.422 & 0.616 & 0.686 & Decreasing \\
\hline BHU Sakesar & 0.599 & 0.725 & 0.825 & Decreasing \\
\hline BHU Aqil Shah & 1 & 1 & 1 & Constant \\
\hline BHU Chak 74/SB & 0.677 & 0.993 & 0.681 & Decreasing \\
\hline BHU Chak 26/SB & 0.838 & 0.839 & 0.999 & Decreasing \\
\hline BHU Chak 28/SB & 0.79 & 0.929 & 0.85 & Decreasing \\
\hline BHU Asianwala & 0.22 & 0.287 & 0.767 & Decreasing \\
\hline BHU Chak 30/NB & 1 & 1 & 1 & Constant \\
\hline BHU Chak 30/SB & 0.645 & 0.722 & 0.893 & Decreasing \\
\hline BHU Chak 33/SB & 0.862 & 0.982 & 0.879 & Decreasing \\
\hline BHU Chak 34/SB & 0.51 & 0.516 & 0.989 & Decreasing \\
\hline BHU Chak 36 NB & 0.684 & 0.84 & 0.814 & Decreasing \\
\hline BHU Chak 38/SB & 0.612 & 0.613 & 0.998 & Increasing \\
\hline BHU Chak 40/SB & 0.362 & 0.392 & 0.924 & Decreasing \\
\hline BHU Chak 43/NB & 0.552 & 0.902 & 0.612 & Decreasing \\
\hline BHU Chak 44/SB & 0.467 & 0.558 & 0.837 & Decreasing \\
\hline BHU Chak 53/SB & 0.306 & 0.306 & 0.999 & Constant \\
\hline BHU Chak 58/NB & 0.299 & 0.299 & 1 & Constant \\
\hline BHU Chak 60/NB & 0.857 & 0.912 & 0.94 & Decreasing \\
\hline BHU Chak 104/SB & 0.617 & 0.804 & 0.768 & Decreasing \\
\hline BHU Chak 107/SB & 0.7 & 0.788 & 0.888 & Decreasing \\
\hline BHU Chak 109/SB & 0.583 & 0.72 & 0.809 & Decreasing \\
\hline BHU Chak 110/SB & 0.482 & 0.664 & 0.725 & Decreasing \\
\hline BHU 75/SB & 0.671 & 0.74 & 0.906 & Decreasing \\
\hline BHU Chak 82/NB & 1 & 1 & 1 & Constant \\
\hline BHU Chak 84/SB & 0.208 & 0.318 & 0.654 & Decreasing \\
\hline BHU Chak 85/SB & 1 & 1 & 1 & Constant \\
\hline BHU Chak 88/SB & 1 & 1 & 1 & Constant \\
\hline BHU Chak 92/NB & 0.657 & 0.942 & 0.697 & Decreasing \\
\hline BHU Chak 94/SB & 0.536 & 0.576 & 0.93 & Decreasing \\
\hline BHU Chak 95/NB & 0.855 & 0.936 & 0.913 & Decreasing \\
\hline BHU Chak 95/SB & 0.472 & 0.58 & 0.813 & Decreasing \\
\hline BHU Chak 98/SB & 0.578 & 0.863 & 0.67 & Decreasing \\
\hline BHU Chak 99/NB & 0.661 & 0.761 & 0.869 & Decreasing \\
\hline BHU Chak 100/SB & 0.917 & 1 & 0.917 & Decreasing \\
\hline BHU Chak 101/NB & 0.449 & 0.661 & 0.679 & Decreasing \\
\hline BHU Chak 101/SB & 0.682 & 0.818 & 0.833 & Decreasing \\
\hline
\end{tabular}




\begin{tabular}{|c|c|c|c|c|}
\hline BHU Chak 103/SB & 0.779 & 0.904 & 0.862 & Decreasing \\
\hline BHU Dharema & 0.732 & 1 & 0.732 & Decreasing \\
\hline BHU Chak 113/SB & 0.723 & 0.764 & 0.946 & Decreasing \\
\hline BHU Chak 31/SB & 0.722 & 0.954 & 0.757 & Decreasing \\
\hline BHU Salam & 0.874 & 0.97 & 0.902 & Decreasing \\
\hline BHU Ratto-Kala & 1 & 1 & 1 & Constant \\
\hline BHU Rakh Chrgah & 0.524 & 0.526 & 0.997 & Increasing \\
\hline BHU Purana Bhalwal & 0.789 & 1 & 0.789 & Decreasing \\
\hline BHU Nabi Shah Khurd & 0.778 & 1 & 0.778 & Decreasing \\
\hline BHU Hazoor Pur & 1 & 1 & 1 & Constant \\
\hline BHU Hathi Wind & 0.687 & 0.754 & 0.911 & Decreasing \\
\hline BHU Gull Pur & 0.715 & 0.763 & 0.937 & Decreasing \\
\hline BHU Dhori & 0.736 & 0.79 & 0.932 & Increasing \\
\hline BHU Deowal & 0.787 & 1 & 0.787 & Decreasing \\
\hline BHU Chak Saida & 1 & 1 & 1 & Constant \\
\hline BHU Chak Mubarak & 1 & 1 & 1 & Constant \\
\hline BHU Chak 18/NB & 0.982 & 1 & 0.982 & Increasing \\
\hline BHU Chak 15/SB & 1 & 1 & 1 & Constant \\
\hline BHU Chak 10/NB & 0.831 & 0.875 & 0.95 & Decreasing \\
\hline BHU Chak 10/ML & 1 & 1 & 1 & Constant \\
\hline BHU Chak 8/ML & 0.549 & 0.655 & 0.838 & Decreasing \\
\hline BHU Chak NO 2/NB & 0.646 & 0.661 & 0.978 & Decreasing \\
\hline BHU Chabba Purana & 0.418 & 0.44 & 0.949 & Decreasing \\
\hline BHU Ali Pur Sayden & 0.391 & 0.527 & 0.743 & Decreasing \\
\hline BHU Kalyan Pur & 0.969 & 0.973 & 0.996 & Decreasing \\
\hline BHU Takhat Hazara & 0.362 & 0.374 & 0.969 & Decreasing \\
\hline BHU Syed Nau & 1 & 1 & 1 & Constant \\
\hline BHU Rural Lilliani & 1 & 1 & 1 & Constant \\
\hline BHU Mateela & 0.52 & 0.632 & 0.823 & Decreasing \\
\hline BHU Kot Raja & 0.501 & 0.552 & 0.908 & Decreasing \\
\hline BHU Korey Kot & 1 & 1 & 1 & Constant \\
\hline BHU Hujjan & 1 & 1 & 1 & Constant \\
\hline BHU Dodha & 0.585 & 0.732 & 0.799 & Decreasing \\
\hline BHU Chak 19/SB & 1 & 1 & 1 & Constant \\
\hline BHU Chak 12/SB & 0.568 & 0.614 & 0.926 & Decreasing \\
\hline BHU Chak Miana & 0.886 & 1 & 0.886 & Increasing \\
\hline BHU Bucha Kalan & 0.759 & 0.925 & 0.821 & Decreasing \\
\hline BHU Behk Lurka & 1 & 1 & 1 & Constant \\
\hline BHU Chak 10/SB & 0.825 & 0.995 & 0.829 & Decreasing \\
\hline BHU Kot Bhi Khan & 1 & 1 & 1 & Constant \\
\hline BHU Mangowal & 0.487 & 0.506 & 0.963 & Decreasing \\
\hline BHU Sabowal & 0.68 & 0.742 & 0.918 & Decreasing \\
\hline BHU Mochiwal & 1 & 1 & 1 & Constant \\
\hline BHU Khawaja Abad & 0.628 & 0.687 & 0.913 & Decreasing \\
\hline BHU Kandan & 1 & 1 & 1 & Constant \\
\hline BHU Kalra & 0.979 & 1 & 0.979 & Decreasing \\
\hline BHU Jahanabad & 0.715 & 0.736 & 0.972 & Decreasing \\
\hline BHU Ghangwal & 0.571 & 0.668 & 0.855 & Decreasing \\
\hline BHU Bakhar Bar & 0.372 & 0.408 & 0.913 & Decreasing \\
\hline BHU Lakhiwal & 0.32 & 0.437 & 0.733 & Decreasing \\
\hline $\begin{array}{l}\text { BHU Thatta Muhammad } \\
\text { Panah }\end{array}$ & 1 & 1 & 1 & Constant \\
\hline BHU Vijh & 0.66 & 0.844 & 0.783 & Decreasing \\
\hline $\begin{array}{l}\text { BHU Thatti Long } \\
\text { (Norewall) }\end{array}$ & 0.494 & 0.575 & 0.859 & Decreasing \\
\hline
\end{tabular}




\begin{tabular}{lcccl} 
BHU Machar Khadi & 0.254 & 0.355 & 0.716 & Decreasing \\
BHU Kudlathi & 0.651 & 0.851 & 0.765 & Decreasing \\
BHU Jahanian Shah & 0.56 & 0.859 & 0.652 & Decreasing \\
BHU Havali Majoka & 0.678 & 0.786 & 0.862 & Decreasing \\
BHU Gul Da Kot & 0.812 & 0.982 & 0.826 & Decreasing \\
BHU Dharah & 0.766 & 1 & 0.766 & Decreasing \\
BHU Dera Jadeed & 0.592 & 0.78 & 0.759 & Decreasing \\
BHU Mubharey Khan & 0.711 & 0.726 & 0.979 & Decreasing \\
BHU Chak 60/SB & 0.493 & 0.557 & 0.884 & Decreasing \\
BHU Chak 50/SB & 1 & 1 & 1 & Constant \\
BHU Chak 152/NB & 1 & 1 & 1 & Constant \\
BHU Chak 115/NB & 0.431 & 0.54 & 0.798 & Decreasing \\
BHU Chak 120/SB & 0.516 & 0.739 & 0.699 & Decreasing \\
BHU Chak121/NB & 0.427 & 0.547 & 0.78 & Decreasing \\
BHU Chak 126/SB & 1 & 1 & 1 & Constant \\
BHU Chak 130/SB & 0.627 & 0.937 & 0.669 & Decreasing \\
BHU Chak 131/SB & 0.987 & 1 & 0.987 & Decreasing \\
BHU Chak 135/SB & 1 & 1 & 1 & Constant \\
BHU Chak 142/NB & 0.917 & 1 & 0.917 & Decreasing \\
BHU Chak 147/148 NB & 0.684 & 0.864 & 0.792 & Decreasing \\
BHU Chak 163/NB & 0.93 & 0.964 & 0.964 & Increasing \\
BHU Shah Nikdar & 0.818 & 1 & 0.818 & Decreasing \\
BHU Shaheen Abad & 1 & 1 & 1 & Constant \\
BHU Sobhaga & 1 & 1 & 1 & Constant \\
\hline
\end{tabular}

